\title{
Studi Uji Kekerasan Rockwell Superficial VS Micro Vickers
}

\author{
Comparation Study Of Hardness Testing \\ By Using Rockwell Superficial VS Microvickers
}

\author{
Magdalena Feby Kumayasari \\ Kementerian Perindustrian \\ Baristand Industri Surabaya \\ Surabaya, Indonesia \\ magdalenafeby@gmail.com
}

\author{
Arif Indro Sultoni \\ Kementerian Perindustrian \\ Baristand Industri Surabaya \\ Surabaya, Indonesia \\ arif.indro.sultoni@gmail.com
}

\begin{abstract}
Abstrak- Pengujian menggunakan mesin uji kekerasan Microvickers membutuhkan preparasi yang cukup sulit. Hal ini membuat banyak produsen yang lebih menyukai menggunakan pengujian Rockwell $\mathrm{T}$ karena proses yang lebih mudah dan cepat. Namun, pada kenyataannya pengujian Rockwell tidak dapat digunakan pada benda uji dengan ketebalan yang cukup tipis dasn lunak, sehingga mengakibatkan banyak sampel yang tidak lolos uji saat diuji menggunakan alat uji kekerasan microvickers pada tingkat kekekerasan lunak. Pada penelitian ini akan dilakukan perbandingan pengujian dengan dua metode kekerasan yang berbeda. Hal ini bertujuan agar mengetahui apakah terdapat perbedaan hasil pengujian terhadap benda yang sama. Kekerasan yang digunakan adalah Rockwell superficial 15 T dan 30 T dengan Microvickers 2 kgf. Dari penelitian ini didapatkan bahwa tidak terdapat perbedaan hasil uji kekerasan antara kedua metode itu, jika dilakukan pemolesan yang benar terhadap benda uji yang akan dilakukan menggunakan microvickers.
\end{abstract}

Kata Kunci-kekerasan, microvickers, Rockwell Superficial

\begin{abstract}
Hardness test with micro hardness method needs complex preparation. It make many manufacturers choose $T$ Rockwell Hardness Method than Microvickers because the simple and ease of preparation. However $T$ Rockwell method can't applied for thin or soft materials that effect to many samples not pass due to standard when tested by using Microvickers. In this research will be compare of the two testing methods. The purpose of the research is to observe the differences of the methods. We use Rockwell superficial $15 \mathrm{~T}$ and $30 \mathrm{~T}$ compare to Microvickers $2 \mathrm{kgf}$. The result of the research is, it was no differences between of the methods if sample of Microhardness test well prepared.
\end{abstract}

Key Word—hardness, microvickers, Rockwell Superficial

\section{PENDAhUluan}

Kekerasan merupakan salah satu metode yang lebih cepat dan lebih murah untuk menentukan sifat mekanik suatu material. Kekerasan bukanlah konstanta fisika, nilainya tidak hanya bergantung pada material yang diuji, namun juga dipengaruhi oleh metode pengujiannya. Apabila metode pengujian yang digunakan berbeda, maka hasil dari sifat mekanisnya pun akan berbeda [1]. Ada beberapa jenis kekerasan yaitu , Ball identation test (Brinnel), Pyramida identation (Vickers), Cone and ball identation test (Rockwell), Uji kekerasan mikro atau knoop hardness [2]. Metode ini dibedakan oleh Indentor dan beban uji yang digunakan.

Kekerasan Rockwell bertujuan untuk menentukan kekerasan suatu material dalam bentuk daya tahan material terhadap indentor berupa bola baja ataupun kerucut intan yang ditekankan pada permukaan material uji tersebut [3]. Nilai keras Rockwell $\mathrm{T}$ adalah angka yang didapat dari perbedaan antara kedalaman bekas penetrasi dari dua tahap pembebanan pada penetrator bola baja yang mempunyai diameter $1,588 \mathrm{~mm}$ (1/16 in) [4][5]. Hal ini ditunjukkan oleh gambar 1.

Berbeda dengan pengujian kekerasan dengan metode Vickers, bertujuan menentukan kekerasan suatu material dalam yaitu daya tahan material terhadap indentor intan yang cukup kecil dan mempunyai bentuk geometri berbentuk piramida seperti ditunjukkan pada gambar 2 [3] . Nilai keras mikro Vickers adalah hasil bagi antara beban tekan statis maksimum dengan luas bidang penetrator [6][7][8].

L.I Heping et al [9], membandingkan kekerasan dua benda yang memiliki ketebalan berbeda yaitu $0,23 \mathrm{~mm}$ dan $0,98 \mathrm{~mm}$. Dari hasil penelitian didapatkan bahwa material reference yang digunakan untuk uji kekerasan Rockwell tidak boleh kurang dari $6 \mathrm{~mm}$ dan Vickers $5 \mathrm{~mm}$. 


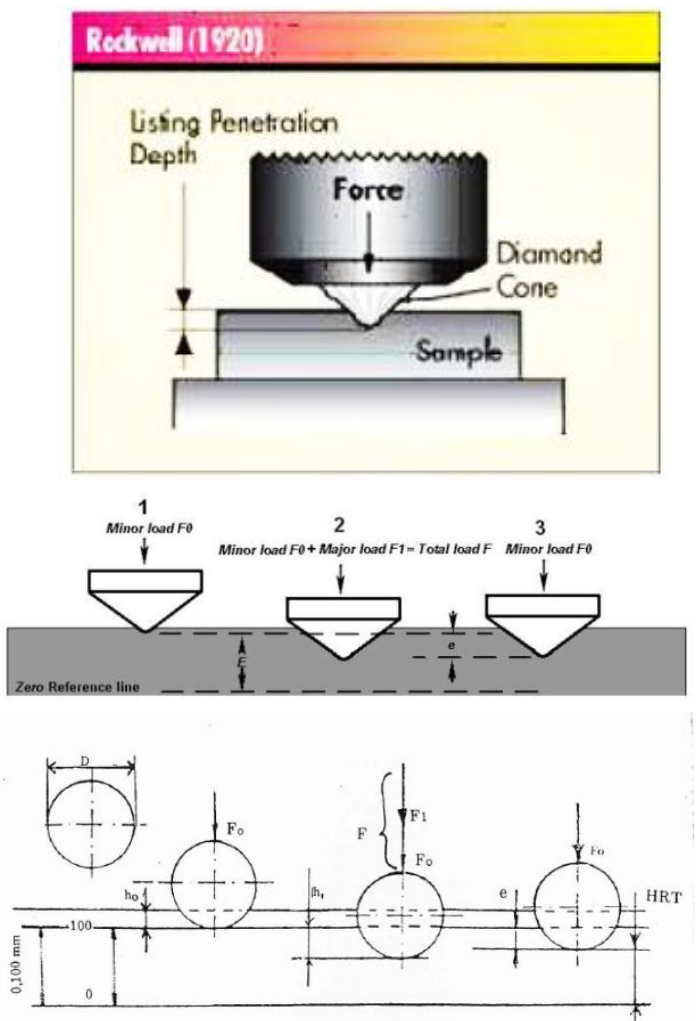

Gambar 1. Prinsip Kerja Metode Pengukuran Kekerasan Rockwell [3][4]

Pada penelitian sebelumnya, dilakukan pengujian kekerasan baja kelas lunak menggunakan metode Mikrovickers. Penelitian dilakukan pada material Baja lembaran dan gulungan canai dingin dengan ketebalan 0,20 mm. Didapatkan nilai kekerasan yang kurang memenuhi standar SNI. Dari hasil pemaparan penelitian, terdapat pertanyaan terkait penggunaan dengan metode lain. Dikarenakan banyak perusahaan yang tidak memiliki alat uji kekerasan microvickers dan mereka hanya memiliki alat uji Rockwell T. Namun kenyataanya, penggunaan alat uji rockwel $\mathrm{T}$ pada ketebalan 0,20 $\mathrm{mm}$ dapat menyebabkan deformasi pada bagian belakang baja tersebut.

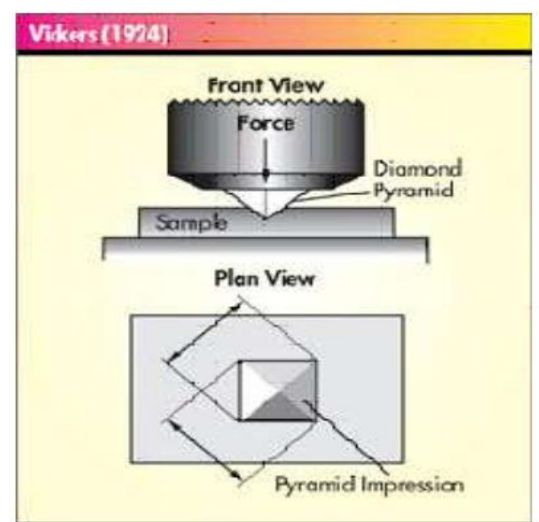

Gambar 2. Prinsip kerja metode pengukuran kekerasan vickers [3]
Pada penelitian ini dilakukan studi perbandingan uji kekerasan Rockwell Superficial $30 \mathrm{~T}$ dan MicroVickers dengan beban uji 2000 gf menggunakan paired sample T test. Hal ini bertujuan untuk mengetahui apakah ada perbedaan antara hasil pengujian yang dilakukan untuk memberikan referensi kepada produsen Logam dan Laboratorium uji.

Paired-Sample $\mathrm{T}$ Test adalah analisis dengan melibatkan dua pengukuran pada subjek yang sama terhadap suatu pengaruh atau perlakuan tertentu. Apabila suatu perlakuan tidak memberi pengaruh, maka perbedaan rata-rata adalah nol. Beberapa contoh aplikasinya adalah :

- Untuk mengetahui pengaruh sebelum dan sesudah perlakuan terhadap suatu subject yang sama.

- Membadingkan dua metode pengukuran yang berbeda atau dua perlakuan yang berbeda yang dikenakan pada suatu subject yang sama.

\section{BAHAN DAN METODE}

Sampel berupa baja lembaran/ Lapis Seng dengan tebal logam dasar 0,80 $\mathrm{mm}$ dan 1,00 $\mathrm{mm}$ tipe Lunak yang diambil dari perusahaan X. Material terlebih dahulu dihilangkan lapisan sengnya untuk kemudian dilakukan uji kekerasan Rockwell 30 $\mathrm{T}$ dan dilakukan pemolesan untuk pengujian microvickers dengan beban 2000 gf.

Eksperimen dilakukan di Laboratorium Uji Baristand Industri Surabaya. Pertama tama sampel dibagi menjadi dua bagian. Sampel pertama untuk pengujian Rockwell 30T . Alat uji yang digunakan pada kekerasan Rockwell $30 \mathrm{~T}$ adalah alat uji Digital Rockwell merk Future Tech Seri FR-3e . Sampel yang kedua dilakukan pemolesan dengan menggunakan kertas gosok nomor 400, 600, 800 dan 1000 sampai didapatkan permukaan yang halus seperti cermin. Hal ini bertujuan untuk memudahkan pembacaan pada layar monitor mesin uji kekerasan MicroVickers. Alat uji yang digunakan adalah Digital Micro Hardness Tester merk High Wood. Permukaan beban uji ditekan dengan penetrator intan berbentuk piramida. Penekanan dilakukan dengan beban statis maksimum dan waktu pembebanan tertentu. Setelah beban diangkat dan memperlihatkan bekas penetrator berbentuk bujur sangkar, selanjutnya diagonal bujur sangkar tersebut diukur untuk menentukan dasar perhitungan nilai keras Vickers [6][10].

\section{HASIL DAN PEMBAHASAN}

\section{A. Perbandingan uji kekerasan Rockwel dan Microvickers pada sampel $0,80 \mathrm{~mm}$}

Pertama tama sampel dibagi menjadi 2, satu sampel dilakukan pengujian rockwel $30 \mathrm{~T}$ dengan beban $30 \mathrm{kgf}$. Tabel 1 merupakan tabel hasil pengujian benda uji dengan ketebalan 0,80 mm menggunakan metode Rockwell $30 \mathrm{~T}$. Dari hasil tersebut kemudian dikonversikan ke dalam Vickers. Hal ini bertujuan agar mudah dalam melakukan perbandingan. 
TABLE I. TABLE hasil PENGUJian Rockwell $30 \mathrm{~T}$ PADA SAMPEL $0,80 \mathrm{MM}$

\begin{tabular}{cc}
\hline Rockwell 30 T & $\begin{array}{c}\text { Vickers } \\
\text { (Konversi) }\end{array}$ \\
\hline $\mathbf{5 8 . 8}$ & 113.3 \\
\hline $\mathbf{5 9 . 8}$ & 116.1 \\
\hline $\mathbf{5 9 . 9}$ & 116.3 \\
\hline $\mathbf{5 9 . 4}$ & 115.1 \\
\hline $\mathbf{5 9 . 8}$ & 116.1 \\
\hline $\mathbf{6 0 . 4}$ & 117 \\
\hline $\mathbf{5 8 . 4}$ & 112 \\
$\mathbf{6 0}$ & 116.4 \\
$\mathbf{5 9}$ & 114 \\
$\mathbf{5 8 . 8}$ & 113.3 \\
$\mathbf{5 9 . 7}$ & 116 \\
$\mathbf{5 8 . 7}$ & 113 \\
\hline $\mathbf{5 8 . 9}$ & 113.7 \\
\hline $\mathbf{5 8 . 3}$ & 111.7 \\
\hline $\mathbf{5 8 . 8}$ & 113.3 \\
\hline
\end{tabular}

Sampel berikutnya dilakukan pengujian micro Vickers dengan beban $2 \mathrm{kgf}$. Tebal awal sampel adalah $0,812 \mathrm{~mm}$, kemudian dipoles dan memiliki tebal akhir 0,761 $\mathrm{mm}$. Sehingga pengurangan ketebalan adalah sebesar 0,051 mm..Hasil dari pengujian Microvickers dapat dilihat pada Tabel 2.

Dari kedua data tersebut kemudian dilakukan analisa paired sample t test. Tabel 3 merupakan hasil dari analisa paired sample t test. Pada Tabel 3, dapat diketahui bahwa nilai dari t hitung adalah $0,419<2,048$ maka $h_{0}$ diterima Sehingga tidak ada perbedaan antara pengujian menggunakan microvickers dengan beban $2 \mathrm{kgf}$.

TABle II. Table hasil Pengujian MicroVickers Pada KETEBALAN 0,80 MM

\begin{tabular}{ccc}
\hline D1 & D2 & HV 2.0 \\
\hline $\mathbf{1 8 3 . 1}$ & 178.3 & 113.5 \\
$\mathbf{1 8 3 . 9}$ & 179.8 & 112.1 \\
$\mathbf{1 8 1 . 5}$ & 181.8 & 112.3 \\
\hline $\mathbf{1 8 0 . 6}$ & 179 & 114.7 \\
\hline $\mathbf{1 8 3}$ & 179.7 & 112.7 \\
\hline $\mathbf{1 8 2 . 1}$ & 178.3 & 114.2 \\
\hline $\mathbf{1 7 5 . 9}$ & 182.5 & 115.4 \\
\hline $\mathbf{1 8 0 . 6}$ & 179 & 114.7 \\
\hline $\mathbf{1 8 0 . 3}$ & 181 & 113.6 \\
\hline $\mathbf{1 8 0 . 1}$ & 181.6 & 113.3 \\
\hline $\mathbf{1 7 9 . 8}$ & 177.4 & 116.2 \\
\hline $\mathbf{1 7 8 . 5}$ & 178.5 & 116.4 \\
\hline $\mathbf{1 7 9 . 3}$ & 183.1 & 112.9 \\
\hline
\end{tabular}

\begin{tabular}{ccc}
\hline D1 & D2 & HV 2.0 \\
\hline $\mathbf{1 7 8 . 1}$ & 178.6 & 116.5 \\
$\mathbf{1 7 9 . 2}$ & 179.7 & 115.1 \\
\hline
\end{tabular}

TABLE III. T-TEST: Two-SAMPLE ASSUMING EquAL VARIANCES 30 T VS HV 2.0 TEBAL $0,80 \mathrm{MM}$

\begin{tabular}{lrr}
\hline & Variable 1 & Variable 2 \\
\hline Mean & 114.4866667 & 114.24 \\
Variance & 3.026952381 & 2.176857143 \\
Observations & 15 & 15 \\
Pooled Variance & 2.601904762 & \\
Hypothesized Mean Difference & 0 & \\
df & 28 & \\
t Stat & 0.418789128 & \\
P(T<=t) one-tail & 0.339282702 & \\
t Critical one-tail & 1.701130908 & \\
P $(T<=t)$ two-tail & 0.678565404 & \\
t Critical two-tail & 2.048407115 & \\
\hline
\end{tabular}

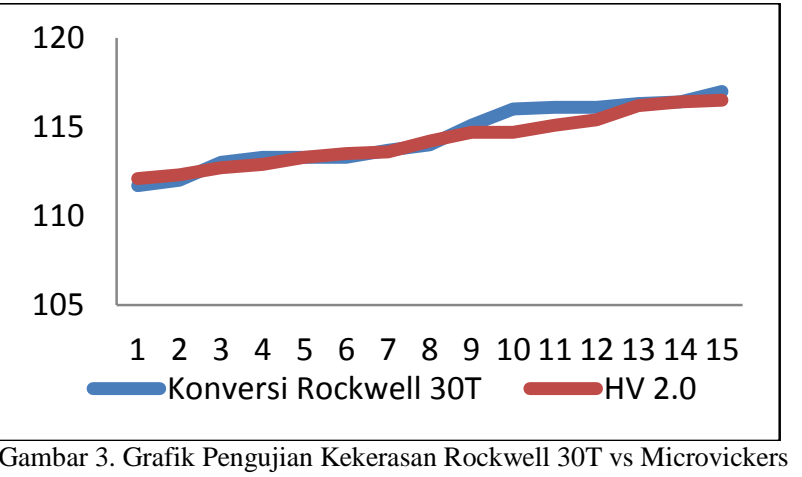

\section{B. Perbandingan uji kekerasan Rockwel dan microvickers pada sampel 1,00 $\mathrm{mm}$}

Tabel IV merupakan hasil dari pengujian kekerasan Rockwell 30 T. Sedangkan table V merupakan hasil dari pengujian microvickers. Kedua hasil uji ini dilakukan paired sample $t$ test untuk melihat apakah ada perbedaan terhadap kedua hasil pengujian ini. Pada table VI, dapat diketahui bahwa bahwa nilai dari t hitung adalah $-2,179>2,056$ maka $h_{o}$ ditolak Sehingga terdapat perbedaan antara pengujian menggunakan microvickers dengan beban $2 \mathrm{kgf}$. Tebal awal dari sampel ini adalah 0,992 mm, kemudian dipoles menjadi 0,950 mm. Sehingga pengurangan ketebalan hanya $0,42 \mathrm{~mm}$. Hal inilah yang menyebabkan terjadi perbedaan hasil antara Rockwell 30 T dengan Microvickers 2 kgf. .

TABLE IV. TABle hasil PENGUJIAN Rockwell 30 T PADA SAMPEL $1,00 \mathrm{MM}$

\begin{tabular}{cc}
\hline Rockwell 30 T & Vickers (Konversi) \\
\hline $\mathbf{5 6 . 3}$ & 106.9 \\
$\mathbf{5 7 . 5}$ & 109.4 \\
$\mathbf{5 6 . 9}$ & 107.8 \\
\hline
\end{tabular}




\begin{tabular}{cc}
\hline Rockwell 30 T & Vickers (Konversi) \\
\hline $\mathbf{5 8 . 8}$ & 113.3 \\
$\mathbf{5 7 . 6}$ & 109.7 \\
$\mathbf{5 6 . 8}$ & 107.7 \\
$\mathbf{5 8 . 4}$ & 112.2 \\
$\mathbf{5 8 . 6}$ & 112.7 \\
$\mathbf{5 7 . 7}$ & 110 \\
$\mathbf{5 7 . 4}$ & 109.1 \\
$\mathbf{5 6 . 4}$ & 107 \\
$\mathbf{5 7 . 8}$ & 110.3 \\
$\mathbf{5 6 . 2}$ & 106.7 \\
$\mathbf{5 6 . 8}$ & 107.7 \\
\hline
\end{tabular}

TABLE V. Table hasil Pengujian MicroVickers Pada KETEBALAN 1,00 MM

\begin{tabular}{ccc}
\hline D1 & D2 & HV 2.0 \\
\hline $\mathbf{1 8 4 . 4}$ & 183.3 & 109.7 \\
$\mathbf{1 8 0 . 5}$ & 180.4 & 113.8 \\
$\mathbf{1 8 2 . 4}$ & 181.4 & 112 \\
$\mathbf{1 7 7 . 4}$ & 179.4 & 116.2 \\
$\mathbf{1 8 4 . 3}$ & 178.9 & 112.4 \\
$\mathbf{1 8 3 . 2}$ & 182.9 & 110.6 \\
$\mathbf{1 7 8 . 2}$ & 174.7 & 119.1 \\
\hline $\mathbf{1 8 2 . 2}$ & 181.3 & 112.2 \\
$\mathbf{1 8 1 . 3}$ & 181.3 & 112.6 \\
$\mathbf{1 8 1 . 8}$ & 177.2 & 115.1 \\
$\mathbf{1 8 2 . 4}$ & 182.4 & 111.4 \\
$\mathbf{1 7 9 . 8}$ & 182.8 & 112.8 \\
$\mathbf{1 7 7 . 7}$ & 180.5 & 115.6 \\
\hline $\mathbf{1 8 3}$ & 180.8 & 112 \\
\hline $\mathbf{1 7 9 . 5}$ & 180.2 & 114.6 \\
\hline $\mathbf{1 8 2 . 1}$ & 181.5 & 112.2 \\
\hline $\mathbf{1 8 5 . 4}$ & 184 & 108.7 \\
\hline
\end{tabular}

Oleh karena itu kami akan melakukan pengujian ulang dengan membandingkan pengujian Rockwell $15 \mathrm{~T}$ dengan Microvickers 2 kgf. Pengujian Rockwel $15 \mathrm{~T}$ menggunakan beban yang lebih kecil, yaitu $15 \mathrm{~kg}$ saja. Diharapkan hasilnya tidak terjadi perbedaan terhadap kedua pengujian tersebut.

TABLE VI. T-TEST: Two-SAMPLE ASSUMing EQUAL VARIANCES $30 \mathrm{~T}$ VS HV 2.0 TEBAL $1,00 \mathrm{MM}$

\begin{tabular}{lrr}
\hline & \multicolumn{1}{l}{ Variable 1 } & \multicolumn{1}{c}{ Variable 2 } \\
\hline Mean & 109.3214286 & 111.0785714 \\
Variance & 4.834120879 & 4.266428571 \\
Observations & 14 & 14 \\
Pooled Variance & 4.550274725 & \\
Hypothesized Mean Difference & 0 & \\
df & 26 & \\
\hline
\end{tabular}

\begin{tabular}{lcc}
\hline & Variable 1 & Variable 2 \\
\hline $\mathbf{t}$ Stat & -2.179401685 \\
$\mathbf{P}(\mathbf{T}<=t)$ one-tail & 0.019275394 \\
t Critical one-tail & 1.705617901 \\
$\mathbf{P}(\mathbf{T}<=t)$ two-tail & 0.038550788 \\
t Critical two-tail & 2.055529418 \\
\hline
\end{tabular}

TABLE VII. TABLE HASIL PENGUJIAN RockWELl 15 T PADA SAMPEL $1,00 \mathrm{MM}$

\begin{tabular}{|cc|}
\hline Rockwell 15 T & Vickers (Konversi) \\
\hline $\mathbf{8 1 . 3}$ & 113.3 \\
$\mathbf{8 1 . 1}$ & 112 \\
$\mathbf{8 1 . 6}$ & 115 \\
$\mathbf{8 0}$ & 106.7 \\
$\mathbf{8 2}$ & 116.7 \\
$\mathbf{8 2}$ & 116.7 \\
$\mathbf{8 0 . 7}$ & 109.3 \\
$\mathbf{8 0 . 6}$ & 108.7 \\
$\mathbf{8 0 . 4}$ & 107.8 \\
$\mathbf{8 1 . 2}$ & 112.7 \\
$\mathbf{8 2 . 2}$ & 117.7 \\
$\mathbf{8 1 . 3}$ & 113.3 \\
$\mathbf{8 2 . 2}$ & 117.7 \\
$\mathbf{8 1 . 6}$ & 115 \\
$\mathbf{8 1 . 4}$ & 114 \\
$\mathbf{8 1 . 4}$ & 114 \\
$\mathbf{8 2}$ & 116.7 \\
\hline
\end{tabular}

TABLE VIII. T-Test: Two-Sample Assuming Equal Variances 15 T VS HV 2.0 TEBAL $1,00 \mathrm{MM}$

\begin{tabular}{lrr}
\hline & Variable 1 & Variable 2 \\
\hline Mean & 113.3705882 & 113 \\
Variance & 12.06845588 & 6.46 \\
Observations & 17 & 17 \\
\hline Pooled Variance & 9.264227941 & \\
Hypothesized Mean Difference & 0 & \\
df & 32 & \\
t Stat & 0.354973943 & \\
P $(T<=t)$ one-tail & 0.362469047 & \\
t Critical one-tail & 1.693888703 & \\
P $(T<=t)$ two-tail & 0.724938094 & \\
$t$ Critical two-tail & 2.036933334 & \\
\hline
\end{tabular}

Tabel VII merupakan hasil dari pengujian Rockwell $15 \mathrm{~T}$. Hasil dari paired sample t test pada kedua pengujian ini ditunjukkan pada tabel VIII. bahwa nilai dari t hitung adalah $0,355<2,037$ maka $h_{o}$ diterima Sehingga tidak ada perbedaan antara pengujian menggunakan microvickers dengan beban 2 kgf dengan Rockwell $15 \mathrm{~T}$ 


\section{KESIMPULAN}

Dari hasil dan pembahasan diataas dapat disimpulkan bahwa pada sampel dengan ketebalan $0,80 \mathrm{~mm}$ tidak terjadi perbedaan antara hasil pengujian Microvickers $2 \mathrm{kgf}$ yang dipoles hingga memiliki perbedaan ketebalan 0,051 mm dengan Rockwell 30 T. Sedangkan pada benda uji $1,00 \mathrm{~mm}$ yang dipoles hingga memiliki pengurangan ketebalan $0,042 \mathrm{~mm}$ terjadi perbedaan jika dilakukan perbandingan antara microvickers $2 \mathrm{kgf}$ dengan Rockwell T. Sehingga dibutuhkan pembanding dengan beban yang lebih kecil yaitu $15 \mathrm{kgf}$. Didapatkan bahwa tidak terjadi perbedaan antara Rockwell $15 \mathrm{~T}$ dan microvickers $2 \mathrm{kgf}$ terhadap benda tersebut.

\section{DAFTAR PUSTAKA}

[1] G. Verdins, D. Kanaska, and V. Kleinbergs, "Selection of the method of hardness test," in Engineering for Rural Development, 2013, pp. 217-222.

[2] N. T. Nugraheni, K. N. Kusuma, R. Y. Sari, and A. Sugiharto, "Uji kekerasan material dengan metode rockwell," Fis. Eksp. Lanjut(Metode Rockwell), pp. 1-9, 2014.
[3] Gordon England, "Material Teknik," in Harndess Testing, 1999, pp. $1-7$.

[4] B. S. Nasional, SNI Cara Uji keras Rockwell T. 1989.

[5] M. Materials, "Standard Test Methods for Rockwell Hardness and Rockwell Superficial Hardness of," Test, vol. 01, no. 01406785, pp. 1-16, 1981.

[6] B. S. Nasional, SNI Mikro vickers beban 0,0098 sampai dengan 49 $N$, cara uji keras. .

[7] W. Conshohocken, "Standard Test Method for Vickers Indentation Hardness of Advanced Ceramics 1," Test, no. March, pp. 1-10, 2003.

[8] ASTM E92-16., "Standard Test Methods for Vickers Hardness and Knoop Hardness of Metallic Materials," ASTM B. Stand., vol. 82, no. July 2010, pp. 1-27, 2017.

[9] L. I. Heping and Z. Xing, "the Application and Effects of Thin Sheet Hardness Reference Materials Without Aging Effect," pp. 19-21, 2007.

[10] ASTM, "ASTM E384-2016, Standard Test Method for Microindentation Hardness of Materials," ASTM Standards, vol. i. pp. 1-43, 2016. 